\title{
Caudal bupivacaine alone versus bupivacaine with ketamine to compare postoperative analgesia
}

\author{
Eesha Shafqat ${ }^{1}$, SameenAsghar ${ }^{2}$, Qandeel Arshad ${ }^{3}$, Shakeel Ahmad $^{4}$ \\ 1. Woman Medical Officer DHA Bahawalpur \\ 2. Demonstrator Quid e Azam Medical College, Bahawalpur \\ 3. Woman Medical Officer THQ, Haroonabad \\ 4. Postgraduation trainee Department of Anaesthesia BVH, Bahawalpur \\ Corresponding Author: eeshamalik@gmail.com
}

\begin{abstract}
Objective: to compare the effectiveness of caudal bupivacain alone and bupivacaine with ketamine in terms of duration of analgesia. Study Design: Randomized controlled trial. Duration and Place: Department of Anaesthesia Quid e Azam Medical College, Bahawalpur from May 2018 to May 2019. Methodology: Study was started after approval from local ethical committee a parental consent was obtained after complete information of study. Main outcome variables are duration of analgesia, pain score, Bromage score. Data analysis was done with SPSS version 23.1. P value $\leq 0.05$ was taken as statistically significant. Results: The mean duration of analgesia and time taken to void urine after surgery of the Group A was $5.80 \pm 2.71$ hours and $4.45 \pm 0.51$ hours, respectively. While, the mean duration of analgesia and time taken to void urine after surgery of the Group B was $12.53 \pm 2.51$ hours and $4.52 \pm 0.53$ hours, respectively. Statistically significant was observed in duration of analgesia. $\mathrm{P}$ value 0.000. Conclusion: Combination of Ketamine $0.5 \mathrm{mg} / \mathrm{kg}$ and bupivacain $0.25 \%$ in a dose of 1 $\mathrm{ml} / \mathrm{kg}$ prolonged the duration of postoperative analgesia toa significant range in comparison with bupivacaine $25 \%$ of $1 \mathrm{ml} / \mathrm{kg}$ alone.
\end{abstract}

Keywords: Caudal block, Spinal anesthesia, Bupivacain, Ketamine, analgesia.

DOI: $10.7176 / \mathrm{JMPB} / 56-01$

Publication date:May $31^{\text {st }} 2019$

\section{Introduction}

Pain is an unpleasant feeling which is most feard symptom of an illness. Human always keep trying to terminate or conquer this unpleasant feeling in any age group ${ }^{1}$. It is a very complicated phenomenon which cannot be described or diagnosed. It is necessary to control the pain in hospitalized patients for better outcomes or early recovery from the disease ${ }^{2}$. Coudal analgesia is a most popular effective and useful regional block in these days. Codual block is a regional analgesic technique mostly used for below diaphragmatic surgeries. It is found to be successful and effective ${ }^{3}$.

Among its disadvantages most common is short duration of action when a single injection of local anaesthetic was given, even bupivacain which is a long acting anaesthetic gives only 4 to 8 hours of analgesic effect ${ }^{4,5}$. To overcome this short duration of action codual catheter was inserted for repeated doses of anaesthetic agent but this method not too much popular because of high risk of infection ${ }^{6}$. Addition of ketamine to an anaesthetic agent enhance the duration of analgesia. Administration of epidural ketamine produce profound the analgesic affects at a level of spinal cord without any adverse effects.

Addition of preservative free drug like ketamine enhanced the time of post operative analgesic effects in patients of below diaphragm surgery ${ }^{7}$. Dose of ketamine caudal block is 
controversial, many previous studies determine the dose of ketamine but it was not justified properly. In a study Semple et al reported that $0.5 \mathrm{mg}$ per $\mathrm{kg}$ is an optimum dose of ketamine for caudal epidural blockade. This local anaesthetic effect is stimulated by $\mathrm{N}$ methyl $\mathrm{D}$ aspirate receptors antagonism also known as NMDA receptors ${ }^{8}$.

Use of ketamine may increase blood pressure and heart rate, because hallucinations raise intracranial and intraocular pressure and provoke acute porphyria ${ }^{9}$. In psychiatric patients ketamine administered with precautions, it increases the sedative effect of medicine in a dose dependent manner. Use of benzodiazepines diminishes the anti depressant role of ketamine. Other than NMDA receptors antagonism ketamine may actually on sigma receptors, muscrinic acetylcholine receptors and antagonized their effects ${ }^{10}$.

\section{Methodology}

Study was started after approval from local ethical committee a parental consent was obtained after complete information of study. Study was completed in Department of Anaesthesia Quid e Azam Medical College, Bahawalpur from May 2018 to May 2019.Patients of age more than 20 years, ASA status I and II and who were selected for below diaphragm surgery were selected for study. Patients with no sensitivity or allergy to bupivacain or ketamine or having caudal injection contraindication such as bleeding disorder, infection at the sight and vertebral column deformities were not included in study. Patients were divided into two groups A and B by lottery method. Patients in group A were given bupivacain $2.5 \%$ with dose of $1 \mathrm{ml}$ per $\mathrm{kg}$ and in group B were given bupivacain $0.25 \%$ with dose of $1 \mathrm{ml}$ per $\mathrm{kg}$ plus ketamine $0.5 \mathrm{mg}$ per $\mathrm{kg}$ preservative free. Bilateral IV lines of $18 \mathrm{G}$ were inserted in dorsal veins of hands. Patients were kept for NPO six hours before surgery. All patients were undergone for general anaesthesia with thiopentone 5 to $6 \mathrm{mg}$ per $\mathrm{kg}$ and inhalational N2o, oxygen and halothane gas. Caudal injection was given before start of surgery and then surgeon was allowed to perform surgery. Patient's non invasive blood pressure, ECG, spo2, heart rate was monitored. When surgical procedure was completed patients were shifted to recovery room and observed for one hour and then observations were done at one hour, four hours, six hours, twelve hours and 24 hours after shifting in ward. Analgesia duration was recorded by VAS core. Duration of analgesia was labeled as time between caudal injection and first analgesia requirement after surgery. Within 24 hours if analgesia was not required then duration of analgesia was noted as 24 hours. Bromage scale was used to evaluate the motor block.

\section{Bromage scale:}

Complete flexion of feet and knees and able to lift legs score 0. Legs cannot be extended or lifted but flexion of knees and feet is present score 1. Flexion of knees and feet both absent score 2. Complete absence of movement in legs and feet score 3.

Data analysis was done by putting data in SPSS version 24. Mean and standard deviation were presented for quantitative data like age, duration of analgesia. Qualitative data was presented as numbers and percentages like gender. Chi square and student t-test were applied to see association among variables. Probability value $\leq 0.05$ was considered as significant.

\section{Results:}

Eighty patients were included in this study. The patients were further analyzed into two Groups as $n=40$ in Group A and $n=40$ in Group B. The mean age, weight and duration of surgery of Group A was $3.71 \pm 1.38$ years, $11.42 \pm 1.86 \mathrm{~kg}$ and $47.62 \pm 3.76$ minutes, respectively. Nature of surgery was observed as urethroplasty in $n=16$ (40\%) patients, 
herniotomy in $n=15(37.5 \%)$ patients and orchidopexy in $n=9(22.5 \%)$ patients. While, the mean age, weight and duration of surgery of Group B was $3.50 \pm 1.55$ years, $11.52 \pm 1.56 \mathrm{~kg}$ and $48.47 \pm 3.01$ minutes, respectively. Nature of surgery was observed as urethroplasty in $\mathrm{n}=27(67.5 \%)$ patients, herniotomy in $\mathrm{n}=9(22.5 \%)$ patients and orchidopexy in $\mathrm{n}=4(10 \%)$ patients. The difference of nature of surgery among the groups was significant (0.044). (Table. I).

Pain score (postoperative) of both the groups at 1, 4, 6, 12 and 24 hours were shown in table II. The difference was statistically significant at 6 and 12 hours, $(p=0.001)$ and $(\mathrm{p}=0.020)$, respectively. Bromage scale (postoperative) of both the groups at 1, 4, 6, 12 and 24 hours were shown in table III. The difference was not statistically significant at any of the hour among the groups.

The mean duration of analgesia and time taken to void urine after surgery of the Group A was $5.80 \pm 2.71$ hours and $4.45 \pm 0.51$ hours, respectively. While, the mean duration of analgesia and time taken to void urine after surgery of the Group B was $12.53 \pm 2.51$ hours and $4.52 \pm 0.53$ hours, respectively. Statistically significant difference was observed for duration of analgesia $(\mathrm{p}=0.000)$. (Table. IV).

Table. I

\begin{tabular}{|l|c|c|c|}
\hline Variables & Group A & Group B & P-value \\
\hline Age (years) & $3.71 \pm 1.38$ & $3.50 \pm 1.55$ & 0.544 \\
\hline Weight (kg) & $11.42 \pm 1.86$ & $11.52 \pm 1.56$ & 0.796 \\
\hline Duration of surgery (minutes) & $47.62 \pm 3.76$ & $48.47 \pm 3.01$ & 0.268 \\
\hline Nature of surgery & $\mathrm{n}=16(40 \%)$ & $\mathrm{n}=27(67.5 \%)$ & \multirow{2}{*}{0.044} \\
\cline { 1 - 3 } Urethroplasty & $\mathrm{n}=15(37.5 \%)$ & $\mathrm{n}=9(22.5 \%)$ & \\
\cline { 1 - 3 } Herniotomy & $\mathrm{n}=9(22.5 \%)$ & $\mathrm{n}=4(10 \%)$ & \\
\cline { 1 - 3 } Orchidopexy & &
\end{tabular}

Table. II

\begin{tabular}{|c|c|c|c|c|c|c|c|}
\hline $\begin{array}{l}\text { Pain score } \\
\text { (postoperative) }\end{array}$ & Groups & $\mathbf{0}$ & 1 & 2 & 3 & $4 />4$ & P-value \\
\hline \multirow[b]{2}{*}{1 hour } & $\mathbf{A}$ & $26(65 \%)$ & $10(25 \%)$ & $2(5 \%)$ & $2(5 \%)$ & $0(0 \%)$ & \multirow[t]{2}{*}{0.869} \\
\hline & B & $29(72.5 \%)$ & $8(20 \%)$ & $2(5 \%)$ & $1(2.5 \%)$ & $0(0 \%)$ & \\
\hline \multirow[b]{2}{*}{4 hour } & $\mathbf{A}$ & $26(65 \%)$ & $7(17.5 \%)$ & $2(5 \%)$ & $2(5 \%)$ & $3(7.5 \%)$ & \multirow[t]{2}{*}{0.350} \\
\hline & B & $32(80 \%)$ & $4(10 \%)$ & $2(5 \%)$ & $2(5 \%)$ & $0(0 \%)$ & \\
\hline \multirow[b]{2}{*}{6 hour } & $\mathbf{A}$ & $12(30 \%)$ & $7(17.5 \%)$ & $2(5 \%)$ & $2(5 \%)$ & $17(42.5 \%)$ & \multirow[t]{2}{*}{0.001} \\
\hline & B & $27(67.5 \%)$ & $6(15 \%)$ & $0(0 \%)$ & $4(10 \%)$ & $3(7.5 \%)$ & \\
\hline \multirow[b]{2}{*}{12 hour } & $\mathbf{A}$ & $2(5 \%)$ & $1(2.5 \%)$ & $1(2.5 \%)$ & $1(2.5 \%)$ & $35(87.5 \%)$ & \multirow[t]{2}{*}{0.020} \\
\hline & B & $7(17.5 \%)$ & $4(10 \%)$ & $4(10 \%)$ & $4(10 \%)$ & $21(52.5 \%)$ & \\
\hline \multirow[b]{2}{*}{24 hour } & $\bar{A}$ & $1(2.5 \%)$ & $1(2.5 \%)$ & $0(0 \%)$ & $0(0 \%)$ & $38(95 \%)$ & \multirow[t]{2}{*}{0.652} \\
\hline & B & $2(5 \%)$ & $1(2.5 \%)$ & $1(2.5 \%)$ & $1(2.5 \%)$ & $35(87.5 \%)$ & \\
\hline
\end{tabular}


Table. III

\begin{tabular}{|c|c|c|c|c|c|c|}
\hline $\begin{array}{l}\text { Bromaeg scale } \\
\text { (postoperative) }\end{array}$ & Groups & $\mathbf{0}$ & 1 & 2 & 3 & P-value \\
\hline \multirow[b]{2}{*}{1 hour } & $\mathbf{A}$ & $25(62.5 \%)$ & $9(22.5 \%)$ & $5(12.5 \%)$ & $1(2.5 \%)$ & \multirow[t]{2}{*}{0.912} \\
\hline & B & $28(70 \%)$ & $7(17.5 \%)$ & $4(10 \%)$ & $1(1.5 \%)$ & \\
\hline \multirow[b]{2}{*}{4 hour } & $\mathbf{A}$ & $31(77.5 \%)$ & $4(10 \%)$ & $5(12.5 \%)$ & $0(0 \%)$ & \multirow[t]{2}{*}{0.854} \\
\hline & B & $33(82.5 \%)$ & $3(7.5 \%)$ & $4(10 \%)$ & $0(0 \%)$ & \\
\hline \multirow[b]{2}{*}{6 hour } & $\mathbf{A}$ & $37(92.5 \%)$ & $1(2.5 \%)$ & $1(2.5 \%)$ & $1(2.5 \%)$ & \multirow[t]{2}{*}{0.562} \\
\hline & B & $39(97.5 \%)$ & $0(0 \%)$ & $0(0 \%)$ & $1(2.5 \%)$ & \\
\hline \multirow[b]{2}{*}{12 hour } & $\mathbf{A}$ & $38(95 \%)$ & $1(2.5 \%)$ & $0(0 \%)$ & $0(0 \%)$ & \multirow[t]{2}{*}{0.603} \\
\hline & B & $39(97.5 \%)$ & $0(0 \%)$ & $0(0 \%)$ & $1(2.5 \%)$ & \\
\hline \multirow[b]{2}{*}{24 hour } & $\mathbf{A}$ & $39(97.5 \%)$ & $0(0 \%)$ & $0(0 \%)$ & $1(2.5 \%)$ & \multirow[t]{2}{*}{0.314} \\
\hline & B & $40(100 \%)$ & $0(0 \%)$ & $0(0 \%)$ & $0(0 \%)$ & \\
\hline
\end{tabular}

Table. IV

\begin{tabular}{|l|c|c|c|}
\hline Variables & Group A & Group B & P-value \\
\hline Duration of analgesia (hours) & $5.80 \pm 2.71$ & $12.53 \pm 2.51$ & 0.000 \\
\hline $\begin{array}{l}\text { Time taken to void urine after } \\
\text { surgery (hours) }\end{array}$ & $4.45 \pm 0.51$ & $4.52 \pm 0.53$ & 0.508 \\
\hline
\end{tabular}

\section{Discussion:}

Study was conducted by Semple et $\mathrm{al}^{11}$ on efficacy and dose of ketamine in codual block and reported that addition of preservative free ketamine enhance the effect of $0.25 \%$ of bupivacain when given in epidural block and optimum dose of ketamine in codual block is $0.5 \mathrm{mg}$ per $\mathrm{kg}$. In the study doses of bupivacain and ketamine ate similar as in our study and conclusion can be compared with our study results and conclusion.

Another study was conducted by Naguib et al $^{12}$ and compared bupivacain $0.25 \%$ alone with bupivacain $0.2 \%$ plus $0.5 \mathrm{mg}$ per $\mathrm{kg}$ ketamine in children who were selected for inguinal herniotomy and concluded that there was not statistically significant difference between the groups in terms of quality and duration of analgesia. In combination group only $7 \%$ patients required rescue analgesia and in other group $20 \%$ patients required rescue analgesia.

A similar study was also conducted by Cook et al ${ }^{13}$ and compared bupivacain $0.25 \%$ plus $0.5 \mathrm{mg}$ per $\mathrm{kg}$ ketamine with clonidine 2 microgram per $\mathrm{kg}$ or epinephrine $5 \mathrm{mg}$ per $\mathrm{ml}$ and concluded that ketamine group provides longer duration of post operative analgesia as compared to clonidine and epinephrine group but in our study we compared ketamine combination bupivacain $0.25 \%$ alone but study results comparable with this study.

Another study was conducted by Martindale SJ et $\mathrm{al}^{14}$ in 2004 , he used bromage scale to access the motor blockade and reported time of motor blockade 2.4 hours, 2 hours and 1.8 hours in bupivacain plus ketamine group and IV ketamine group respectively. This study shows higher duration of analgesia when bupivacain was given in codual epidural block as compared to ketamine plus bupivacain. Results of this study were controversial to our study results. 
Kaur D et a ${ }^{15}$ conducted a similar study on children and access the duration of analgesia after surgery after ketamine plus bupivacain and bupivacain alone. He reported that addition of ketamine with bupivacain enhance the analgesia duration in post operative time as compared to codyal bupivacain alone. In his study main duration of analgesia was $5.36 \pm 0.98$ hour in bupivacain alone group and $10.18 \pm 2.24$ in combination group. $\mathrm{P}$ value was 0.001 which shows significance of result. This study is comparable with our study.

In a study conducted by Samad $\mathrm{R}$ et $\mathrm{al}^{16}$ on comparison of bupivacain plus tramadol and bupivacain plus ketamine and demonstrated that combination of bupivacain plus tramadol provides longer duration of analgesia as compare to ketamine and bupivacain. This combination also provides deep sedation. This study is comparable with our study. Singh J et $\mathrm{al}^{17}$ conducted a study on comparison of ketamine plus bupivacain, bupivacain plus normal saline and bupivacain plus clonidine and demonstrated that combination of clonidine plus bupivacain provides longer duration of analgesia.

When we concern about the dose of ketamine in bupivacain $0.25 \%$ Panjabi et al ${ }^{18}$ conducted a study and recommended that $0.5 \mathrm{mg} / \mathrm{kg}$ is a standard dose of ketamine when added in bupivacain for better analgesic effect and sedation of patients. He compared $0.5 \mathrm{mg} / \mathrm{kg}$ ketamine with $0.25 \mathrm{mg} / \mathrm{kg}$ ketamine and side effects also limited. In a study Nasr et al ${ }^{19}$ reported that use of $0.5 \mathrm{mg} / \mathrm{kg}$ ketamine in $0.25 \%$ bupivacain provides sufficient effect of duration of analgesia.

In a study Findlow $\mathrm{D}$ et $\mathrm{al}^{20}$ compare the bupivacain and combination of bupivacain with ketamine and reported that combination of ketamine plus bupivacain provides longer duration of analgesia about $20 \%$ greater time of analgesic effect. Results of this study are also identical to our study that for purpose of duration of analgesia combination of bupivacain and ketamine $0.5 \mathrm{mg} / \mathrm{kg}$ is an ideal choice.

\section{Conclusion:}

Results of our study reveal that combination of Ketamine $0.5 \mathrm{mg} / \mathrm{kg}$ and bupivacain $0.25 \%$ in a dose of $1 \mathrm{ml} / \mathrm{kg}$ prolonge the duration of postoperative analgesia to a significant range in comparison with bupivacaine $25 \%$ of $1 \mathrm{ml} / \mathrm{kg}$ alone.

\section{References}

1. Kanaujia SK, Chaudhary AK. Comparative study of postoperative caudal analgesia for pediatric patients undergoing lower abdominal surgeries. 2016;5(6):1008-1011.

2. Al-Zaben KR, Qudaisat IY, Abu-Halaweh SA, Al-Ghanem SM, Al-Mustafa MM, Alja'bari AN et al. Comparison of caudal bupivacaine alone with bupivacaine plus two doses of dexmedetomidine for postoperative analgesia in pediatric patients undergoing infra-umbilical surgery: a randomized controlled double-blinded study. Paediatr Anaesth. 2015;25(9):883-90.

3. Santha R, George G. Comparison between caudal bupivacaine plus ketamine and bupivacaine plus tramadol for post-operative pain relief in lumbar spine surgeries. J. Evolution Med. Dent. Sci. 2017;6(1):33-35.

4. Thendralarasu IC, Balamurugan RJ. Caudal analgesia in paediatrics: comparison between bupivacaine alone and in combination with ketamine for postoperative analgesia in GVMC, Vellore. J. Evolution Med. Dent. Sci. 2016;5(102):7478-7483.

5. Chan KH, Shah A, Moser EA, Szymanski K, Whittam BM, Misseri R et al. Comparison of Intraoperative and Early Postoperative Outcomes of Caudal vs Dorsal Penile Nerve Blocks for Outpatient Penile Surgeries. Urology. 2018;118:164-171. 
6. Solanki N, Engineer S, Jansari D, Patel R. Comparison of caudal tramadol versus caudal fentanyl with bupivacaine for prolongation of postoperative analgesia in pediatric patients. Saudi J Anaesth. 2016;10(2):154-160.

7. Sanwatsarkar S, Kapur S, Saxena D, Yadav G, Khan NN. Comparative study of caudal clonidine and midazolam added to bupivacaine during infra-umbilical surgeries in children. Journal of Anaesthesiology, Clin Pharmacol. 2017;33(2):241-247.

8. Farrag WSH, Ibrahim AS, Mostafa MG, Kurkar A, Elderwy AA. Ketamine versus magnesium sulfate with caudal bupivacaine block in pediatric inguinoscrotal surgery: A prospective randomized observer-blinded study. Urol Ann. 2015;7(3):325-329.

9. Ahuja S, Yadav S, Joshi N, Chaudhary S, Madhu SV. Efficacy of caudal fentanyl and ketamine on post-operative pain and neuroendocrine stress response in children undergoing infraumbilical and perineal surgery: A pilot study. Journal of Anaesthesiology, Clin Pharmacol. 2015;31(1):104-109.

10. Akbas M, Titiz TA, Ertugrul F, Akbas H, Melikoglu M. Comparison of the effect of ketamine added to bupivacaine and ropivacaine, on stress hormone levels and the duration of caudal analgesia. Acta Anesthesiol Scand. 2005;49:1520-6.

11. Semple D, Findlow D, Aldridge LM, Doyle E. The optimal dose of ketamine for caudal epidural blockade in children. Anaesthesia. 1996;51:1170-2.

12. Naguib M, Sharif AM, Seraj M, el Gammal M, Dawlatly AA. Ketamine for caudal analgesia in children: Comparison with caudal bupivacaine. $\mathrm{Br} J$ Anaesth. 1991;67:559-64.

13. Cook B, Grubb DJ, Aldridge LA, Doyle E. Comparison of the effects of adrenaline, clonidine and ketamine on the duration of caudal analgesia produced by bupivacaine in children. Br J Anaesth. 1995;75:698-701.

14. Martindale SJ, Dix P, Stoddart PA. Double-blind randomized controlled trial of caudal versus intravenous $\mathrm{S}(+)$-ketamine for supplementation of caudal analgesia in children. Br J Anaesth. 2004;92:344-7.

15. Kaur D, Anand S. Comparison between caudal bupivacaine and bupivacaine with ketamine for postoperative analgesia in children: A prospective randomized clinical study. Anesth Essays Res. 2016;10(3):488-92.

16. Samad R, Shah TH. Comparison of Caudal TramadolBupivacaine and KetamineBupivacaine For Postoperative Analgesia In Children. J Surg Paki. 2013;18(2):54-58.

17. Singh J, Shah RS, Vaidya N, Mahato PK, Shrestha S, Shrestha BL. Comparison of Ketamine, Fentanyl and Clonidine as an Adjuvent During Bupivacaine Caudal Anesthesia in Pediatric Patients. Kathmandu Univ Med J 2012;39(3):25-29.

18. Panjabi N, Prakash S, Gupta P, Gogia AR. Efficacy of three doses of ketamine with bupivacaine for caudal analgesia in pediatric inguinal herniotomy. Reg Anesth Pain Med 2004;29:28-31.

19. Nasr DA, Abdelhamid HM. The efficacy of caudal dexmedetomidine on stress response and postoperative pain in pediatric cardiac surgery. Ann Card Anaesth 2013;16:109-114.

20. Findlow D. Comparison of caudal block using bupivacaine and ketamine with ilioinguinal nerve block for orchidopexy in children. Anesthesia. 1997;52:1090-1113. 